\title{
Antimicrobial Activity of Moringa oleifera Leaf Extracts against Streptococcus pneumoniae Isolates
}

\author{
Richard Kagia, Carolyne Chepkirui, Michael Walekhwa, Teresa Ogeto, Titus Suge, Mary Murithi, \\ Ferdinand Ndubi, Esbon Wambugu, Hadan Baiwo, Zablon Malago, and Fred Kipsang
}

\section{ABSTRACT}

Pneumococcal diseases (PD) constitute a major threat to the global public health stability especially in the developing world. The risk is greater for children under 5 years, the elderly and persons living with compromised immune systems. Antibiotic agents, conjugate as well as polysaccharide vaccines have been available for several decades and have saved many lives. However, the burden of PD has consistently remained high resulting in poor quality of life and strained economic tenets. Constant resistance to available antibiotic agents and low access to vaccines constitute major setbacks to efforts meant to scale down the burden of PD. The need to explore more viable and promising options is not only urgent but also untenable. We profiled the pharmacological credentials of Moringa oleifera extracts as a possible efficacious alternative to conventional prophylactic and therapeutic interventions. Methanol and ethanol extracts of air-dried leaves of Moringa oleifera plant were subjected to phytochemical screening to identify the presence of carbohydrates, proteins, saponins, alkaloids, tannins, flavonoids, phyto-sterols, oils, and fats. A working solution of the two extracts was prepared by dissolving $20 \mathrm{mg} \& 40 \mathrm{mg}$ of the extracts in $1 \mathrm{ml}$ of $99.9 \%$ dimethyl sulfoxide solvent. Sterilized $6 \mathrm{~mm}$ blank discs were loaded with $20 \mathrm{ul}$ of the final extract concentrations and incubated at $45^{\circ} \mathrm{C}$ for 20 hours. Dimethyl sulfoxide (100\% DMSO) impregnated discs and $30 \mathrm{mcg}$ ceftriaxone antibiotics were used as negative and positive controls respectively. Colon morphology on gentamicin blood agar (GBA) and blood agar (BA), gram staining and optochin assay were leveraged to identify Streptococcus pneumoniae. Disk diffusion method on Muller Hinton agar was used to evaluate sensitivity of Streptococcus pneumoniae to the subject extracts. Methanol and ethanol extracts were found to contain carbohydrates, proteins, saponins, tannins, flavonoids, steroids, fixed oils, alkaloids, and cardiac glycosides. Both extracts were found to contain flavonoids, tannins, and phenolic compounds. Ethanol \& methanol extracts had lower anti-bacterial activity as compared to the $30 \mathrm{mcg}$ positive control. Further exploration to reveal the anti-bacterial activity of aqueous based extracts on Streptococcus pneumoniae is strongly recommended.

Keywords: Moringa oleifera, Streptococcus pneumoniae and Pneumococcal disease.
Published Online: August 08, 2021

ISSN: $2684-5199$

DOI: $10.24018 /$ ejbio.2021.2.4.223

Richard Kagia

School of Pharmacy, Kabarak

University, Kenya.

(e-mail: richkagz@gmail.com)

Carolyne Chepkirui

School of Science, Engineering \& Technology, Kabarak University, Kenya.

(e-mail: carochep2005@gmail.com)

Michael Walekhwa

School of Medicine \& Health Sciences, Kabarak University, Kenya.

(e-mail: walekhwam ${ }^{\circledR}$ gmail.com)

Teresa Ogeto

School of Medicine \& Health Sciences, Kabarak University, Kenya.

(e-mail: tkogeto08 ${ }^{\circledR}$ gmail.com)

Titus Suge

School of Pharmacy, Kabarak University, Kenya.

(e-mail: sugetitus ${ }^{@}$ yahoo.com)

Mary Murithi

School of Pharmacy, Kabarak University, Kenya.

(e-mail: murithimary11@gmail.com)

Ferdinand Ndubi

School of Pharmacy, Kabarak

University, Kenya.

(e-mail: ferdndubi@yahoo.com)

Esbon Wambugu

School of Pharmacy, Kabarak University, Kenya.

(e-mail: wambuguesbon ${ }^{\circledR}$ gmail.com)

Hadan Baiwo

School of Medicine \& Health Sciences, Kabarak University, Kenya.

(e-mail: hkipleting ${ }^{\circledR}$ kabarak.ac.ke)

Zablon Malago

School of Pharmacy, Kabarak University, Kenya.

(e-mail: zablonlister ${ }^{\circledR}$ gmail.com)

Fred Kipsang

School of Medicine \& Health Sciences,

Kabarak University, Kenya.

(e-mail: fkipsang ${ }^{\circledR}$ kabarak.ac.ke)

*Corresponding Author

Michael Walekhwa 


\section{INTRODUCTION}

Pneumococcal disease (PD) due to Streptococcus pneumoniae constitutes a major burden to global public health dynamics as well as economies [1]. Morbidity and mortality due to PD across all age groups has increasingly \& consistently remained high. This is despite availability of effective modern medicines and vaccines. Low \& middle income countries (LMICs) are especially more affected and therefore experience the most unfavorable prognosis [2]. An estimated 39,750 people living in America are infected with the invasive form of PD annually [3]. Out of this, an average 4,000 cases end up in death. Accurate and updated statistics on prevalence of both non-invasive and invasive PD in LMICs are either lacking or scanty. However, given the low vaccine coverage, ineffectual healthcare systems as well as dismal living conditions, it won't be unreasonable to imagine that prevalence is much higher. The need for continuous research meant to unravel products that show promising therapeutic and prophylactic capacity as well as new drug targets cannot be overemphasized.

Exploration of natural products (NPs) over time has revealed their diverse and multi-dimensional chemical structures [4]. These structures have consequently been extensively leveraged in the development of novel drug candidates. The three-dimensional chemical and steric structural orientation of NPs especially affords them an edge over modern medicines as it accentuates efficiency and selectivity of molecular targets. Artemisinin and its analogues, Vinca alkaloids (Catharanthus roseus) as well as terpene paclitaxel (Taxus baccata) used for management of malaria and cancer respectively, are good examples of successful drugs derived from NPs for management of emerging \& re-emerging health challenges. The world has an estimated 250,000 to 500,000 plant species [5]. Out of which only a handful have been explored and appropriately profiled for bioactive capacity. Obviously then incredible plant therapeutic potential still remains largely untapped.

Moringa oleifera is a naturally occurring shrub which belong to the family of Moringaceae, distributed globally [6]. The seeds, leaves, stem, bark, roots, and flowers of this plant are extensively used in treatment of various infections [7], [8]; bronchitis [9], chest congestion and asthma [9], [10]. The leaves are a rich source of flavonoids, fatty acids and phenolics which are responsible for several pharmacological properties [11]. Moringa oleifera extracts have shown antidiabetic [11], [12], anti-ulcer [13], anti-epileptic [13], anticancer, hepato-protective [14], [15], antibacterial [16], [17], antifungal and cholesterol lowering activities.

Moringaceae is monogeneric and contains 13 species. Most listed pharmacological importance is relevant to Moringa oleifera. The remaining 12 are yet to be adequately explored. Of concern still is the capacity of researchers to differentiate among the diverse species of Moringa. Further, organism specific bioactivity data is notably limited or completely lacking. We therefore explored the antibacterial activity of Moringa oleifera against Streptococcus pneumoniae.

\section{MATERIALS AND METHODS}

\section{A. Collection and Identification of Plant Material}

The leaves of Moringa oleifera were collected from Siaya County in Bondo constituency, sub-county Majiwa, Kenya. The plant was identified and authenticated by a Botanist at Kabarak University Herbarium where a voucher specimen was deposited.

\section{B. Phytochemical Investigation of the Extracts}

The methanol and ethanol extracts were subjected to phytochemical screening to identify the presence of carbohydrates, proteins, saponins, alkaloids, tannins, flavonoids, phyto-sterols, oils, and fats. The tests done included Molisch's test, Benedict's test, Millon's test, Xanthoproteic test, Biuret test, Ninhydrin test, Froth /foam test, Hemolytic test, Ferric chloride test, Gelatine test, Iodine test, Potassium dichromate test, Lead acetate test, Mayer's test, Wagner's test, Hager's test, Draggendoff test, Alkaline reagent test, Lead acetate test, Magnesium ribbon test, Liebermann's test, Salkowski test, Kedde test, Keller-killiani test, Borntrager test, Modified Borntrager test, Fluorescence test, Oil stain test and Saponification test.

\section{Preparation and Extraction of the Leaf Extracts}

The air-dried leaves were powdered using a mortar and pestle; the fine particles were separated and stored in clean containers. One forty grams (140 g) of the powdered leaves were extracted with $(400 \mathrm{ml} \times 3)$ of n-hexane, with constant shaking under a mechanical shaker. The extracts were concentrated in a vacuum evaporator, and then transferred into a sterile beaker [18]. In similar process petroleum ether, methanol and ethanol extracts were obtained.

The yield $(\% \mathrm{w} / \mathrm{w})$ from the extracts was calculated as follows:

$$
\text { Yield }(\%)=\mathrm{W}_{2}-\mathrm{W}_{1} / \mathrm{W}_{0} \times 100
$$

where, $\mathbf{W}_{\mathbf{2}}$ is the weight of the extract and the container, $\mathbf{W}_{\mathbf{1}}$ weight of the empty container and $\mathbf{W}_{\mathbf{0}}$ the weight of the plant powder [19]

\section{Preparation of Impregnated Discs}

A stock solution of methanol and ethanol plant extracts were prepared by dissolving $20 \mathrm{mg}$ and $40 \mathrm{mg}$ of the extracts with one $\mathrm{ml}$ of $99.9 \%$ dimethyl sulfoxide solvent respectively. Three $20 \mathrm{ul}$ of the final concentration of $20 \mathrm{mg} / \mathrm{ml}$ and $40 \mathrm{mg} / \mathrm{ml}$ were then used to impregnate the sterilized $6 \mathrm{~mm}$ blank discs (Oxide, UK). Negative controls of dimethyl sulfoxide loaded discs were used for methanolic and ethanolic extracts. The discs that had been impregnated were dried fully in a $45^{\circ} \mathrm{C}$ incubator for 20 hours before their application on the Streptococcus pneumoniae bacterial lawn. The standard Ceftriaxone $30 \mathrm{mcg}$ antibiotic discs (HiMedia Laboratories, India) were used as positive controls. 


\section{E. Identification of Bacterial Strains}

All bacterial samples were cultured on blood agar with gentamicin (GBA). These plates were initially evaluated on the basis of colony morphology. Samples whose colonies exhibited $\alpha$-hemolysis, appeared greyish, mucoid and with a pinpoint outer curvature were classified as Streptococcus pneumoniae to await further evaluation. The samples were taken through a gram-staining process. Those that appeared gram-positive and lancet shaped with a di-cocci consistency were placed on a shortlist for final definitive evaluation. Candidates on the shortlist were sub cultured on blood agar and, after 24 hours, the colonies were inoculated evenly on Mueller Hinton (MH) with 5\% sheep blood. Optochin discs were then dispensed on to the $\mathrm{MH}-5 \%$ plates using sterile forceps and incubated in anaerobic conditions for a period of 24 hours. Samples with at least $14 \mathrm{~mm}$ inhibition zones around optochin disks were confirmed to be Streptococcus pneumoniae isolates.

\section{F. Antimicrobial Susceptibility Testing}

Disc diffusion method was carried out according to the Clinical Laboratory Standards Institute (CLSI) guidelines [20]. Specific procedures are explained in the subsequent items.

\section{G. Inoculums and Inoculation Procedure}

The disc diffusion method was performed in reference to the available CLSi procedures. This was done so as to assess the antibacterial activity of the plant extracts. Streptococcus pneumoniae bacterial culture that had been adjusted to 0.5 McFarland standard was used to lawn $6 \mathrm{~mm}$ Muller Hinton agar (HiMedia Laboratories, India) plates evenly. A sterile cotton swab was used. In order to avoid loss of viability, the bacterial suspension was used within 15 minutes of standardization. The plates were dried by leaving their lids ajar for 15 minutes and then used for the sensitivity test.

\section{H. Application of Impregnated Discs}

The extract impregnated discs were placed on the MuellerHinton agar surface using sterile forceps. Every test plate comprised three discs; one positive control, which is a standard commercial antibiotic disc (ceftriaxone $30 \mathrm{mcg}$ ), one negative control (100\% DMSO), and one treated disc. Besides the controls, each plate had one treated disc placed equal distance to each other. The culture plates were then turned upside down in the incubator at $37{ }^{\circ} \mathrm{C}$ for 24 hours under $5 \%$ carbon IV oxide conditions. After the incubation, the plates were then examined for the inhibition zone. The resulting zones of inhibition were measured using vernier calipers and results tabulated. The tests were repeated three times to ensure reproducibility

\section{RESULTS AND DiSCUSSION}

Phytochemicals are considered to be secondary metabolites and have been used as medicines throughout history [21]. Phytochemical screening of Moringa oleifera methanolic and ethanolic leaf extracts revealed presence of carbohydrates, proteins, saponins, tannins, flavonoids, steroids, fixed oils, alkaloids, and cardiac glycosides as shown in Table I. A study conducted by [22] also revealed similar phytochemicals in aqueous and ethanolic extracts of M. oleifera leaf extracts. Another study done by [23] also found similar phytochemicals in aqueous and ethanolic extracts of $M$. oleifera except phenols and steroids which were absent in their study but present in this study.

\begin{tabular}{ccc}
\multicolumn{3}{c}{ TABLE I: PHYTOCHEMICAL SCREENING RESULTS } \\
\hline Phytochemicals & $\begin{array}{c}\text { Methanolic } \\
\text { Extract }\end{array}$ & $\begin{array}{c}\text { Ethanolic } \\
\text { Extract }\end{array}$ \\
\hline Carbohydrates & + & + \\
Proteins & + & + \\
Saponins & + & + \\
Tannins \& phenolic compounds & + & + \\
Flavonoids & + & + \\
Terpenoids \& steroids & + & + \\
Coumarones & + & + \\
Fixed oils \& fats & + & + \\
Cardiac glycosides & + & - \\
Anthraquinone glycosides & - & + \\
Alkaloids & + & + \\
\hline
\end{tabular}

+ indicates presence while - indicates absence.

Both the methanolic and ethanolic extracts contained flavonoids which are known to be DNA-protecting and thus $M$. oleifera can be used as a precursor for anticancer medications [24]. [25] reported that the most predominant flavonoids in $M$. oleifera leaf extracts are quercetin \& kaempferol. This study indicates the presence of tannins and phenolic compounds in $M$. oleifera which indicates its potential to be used as an antidiabetic. It may also possess antitumor, cardio protective and anti-inflammatory effects [26]. The most common phenolic acids in M. oleifera are caffeic acid, coumaric acid, ellagic acid, gallic acid and chlorogenic acid while the most common alkaloid is N, $\alpha-\mathrm{L}$ rhamnopyranosyl vincosamide, an indole alkaloid [27].

Both ethanolic and methanolic extracts had lower antibacterial activity against $S$. pneumonia, compared to ceftriaxone as shown in Table 2. Though minimal, this indicates that Moringa oleifera may have antibacterial activity, a finding supported by other works which found antibacterial activity of $M$. oleifera against Escherichia coli, Staphylococcus aureus, Proteus vulgaris, Streptococcus mutans, Bacillus subtilis, Staphylococcus epidermidis and Pseudomonas aeruginosa. In these studies, the ethanolic extract had the highest antibacterial activity compared to methanolic and aqueous extracts unlike our study where both methanolic and ethanolic extracts had similar antibacterial activity [28], [29]. Antibacterial activity of M. Oleifera is not limited to the leaf but has been shown to be in the root, flower, bark, seed and in essence the whole plant [30].

TABLE II: ANTIBACTERIAL ACTIVITY OF ETHANOLIC AND METHANOLIC EXTRACTS OF MORINGA OLEIFERA AGAINST STREPTOCOCCUS PNEUMONIAE

\begin{tabular}{|c|c|c|c|c|}
\hline & & $\begin{array}{c}\text { Test } 1 \\
\text { (Zone of } \\
\text { inhibition } \\
\text { in } \mathrm{mm} \text { ) }\end{array}$ & $\begin{array}{c}\text { Test } 2 \\
\text { (Zone of } \\
\text { inhibition } \\
\text { in } \mathrm{mm} \text { ) }\end{array}$ & $\begin{array}{c}\text { Test } 3 \\
\text { (Zone of } \\
\text { inhibition } \\
\text { in } \mathrm{mm} \text { ) }\end{array}$ \\
\hline Ethanolic & $20 \mathrm{mg} / \mathrm{ml}$ & 9 & 9 & 9 \\
\hline Extract & $40 \mathrm{mg} / \mathrm{ml}$ & 11 & 11 & 11 \\
\hline Methanolic & $20 \mathrm{mg} / \mathrm{ml}$ & 9 & 9 & 9 \\
\hline Extract & $40 \mathrm{mg} / \mathrm{ml}$ & 10 & 11 & 11 \\
\hline \multicolumn{2}{|c|}{$\begin{array}{l}\text { Positive (Ceftriaxone } 30 \\
\mathrm{mcg})\end{array}$} & 40 & 40 & 40 \\
\hline \multicolumn{2}{|c|}{$\begin{array}{c}\text { Negative Control (100\% } \\
\text { DMSO) }\end{array}$} & 7 & 7 & 7 \\
\hline
\end{tabular}


Flavonoids, saponins, terpenoids and alkaloids are credited for the antibacterial activity of $M$. oleifera. Flavonoids are thought to cause antibacterial activity through various mechanisms. One of the mechanisms is inhibiting synthesis of nucleic acid by inhibiting DNA gyrase, especially caused by quercetin (one of the most common flavonoids found in M. oleifera) [31]. Other mechanisms of flavonoids include cytoplasmic membrane function inhibition, energy metabolism inhibition, cell attachment reduction and porin inhibition on the cell membrane [32]. Saponins may act as antibacterial agents by cell wall degradation and cytoplasmic membrane disruption. The mechanism of action of terpenoids is yet to be well elucidated. They are thought to act by increasing permeability of cell membrane or cell membrane rupture or target enzymes inhibition. Alkaloids are generally bactericidal and are thought to act by inhibiting nucleic acid synthesis either by dihydrofolate reductase inhibition or topoisomerase I \& II inhibition [33]. These phytochemicals may act synergistically to cause antibacterial activity.

While ethanolic and methanolic based extracts have demonstrated promising anti-bacterial activity against Streptococcus pneumoniae, the effect is not potent enough to warrant a strong recommendation to have it used as an alternative to conventional antibiotic interventions. However, this study was limited by the fact that aqueous based extracts were not explored. We recommend further studies to explore the effect of aqueous based extracts on Streptococcus pneumoniae.

\section{CONFLICT OF INTEREST}

Authors declare no conflict of interest.

\section{REFERENCES}

[1] Jones, K. E., Patel, N. G., Levy, M. A., Storeygard, A., Balk, D., Gittleman, J. L., \& Daszak, P., "Global trends in emerging infectious diseases," Nature, 2008. 451(7181), 990-993. https://doi.org/10.1038/nature06536.

[2] Feldman, C., \& Anderson, R., "Recent advances in the epidemiology and prevention of Streptococcus pneumoniae infections," F1000Research, 2020. https://doi.org/10.12688/f1000research.22341.1.

[3] Sanchez, E. and J. L. B., "Pneumococcal Infections (Streptococcus pneumoniae)," Retrieved from: https://emedicine.medscape.com/article/225811-overview. 2020

[4] Ghrairi, T., Jaraud, S., Alves, A., Fleury, Y., El Salabi, A., \& Chouchani, C., "New Insights into and Updates on Antimicrobial Agents from Natural Products," BioMed. Research International. 2019, https://doi.org/10.1155/2019/7079864.

[5] Kirubakari, B., Shanmugapriya, Sangeetha, T., Vijayarathna, S., Chen, Y., Kanwar, J. R., Sasidharan, S., "Antibacterial and antifungal agents of higher plants," Natural Bio-active Compounds: Volume 1: Production and Applications 2019, pp. 493-508. https://doi.org/10.1007/978-981-13-7154-7_16.

[6] Abdull Razis, A. F., Ibrahim, M. D., \& Kntayya, S. B., "Health Benefits of Moringa oleifera," Asian Pacific Journal of Cancer Prevention, $2014 . \quad 15(20), \quad 8571-8576$. https://doi.org/10.7314/APJCP.2014.15.20.8571.

[7] Patel, K, P; M. M., Kanzariya, N. R., Vaghela, K. R., Patel, D. R. K., \& Patel, D. N. J., "In-Vitro Hepatoprotective Activity of Moringa Oleifera Lam. Leave on Isolated Rat Hepatocytes," 2010. https://www.researchgate.net/publication/286757389_Invitro_hepatoprotective_activity_of_Moringa_oleifera_Lam_Leave_on _isolated_rat_hepatocytes.

[8] Stohs, S. J., \& Hartman, M. J., "Review of the Safety and Efficacy of Moringa oleifera," Phytotherapy Research, 2015. 29(6), 796-804. https://doi.org/https://doi.org/10.1002/ptr.5325.
[9] Mehta, A., \& Agrawal, B., "Investigation into the mechanism of action of Moringa oleifera for its anti-asthmatic activity," Advances in Traditional Medicine, 2008. 8(1), 24-31. https://doi.org/10.3742/OPEM.2008.8.1.024.

[10] Tahir, K., Mugal, M. T., \& Haq, I. U., "Moringa oleifera: a natural giftA review," 2010, 2(11), 775-781.

[11] Anwar, F., Latif, S., Ashraf, M., \& Gilani, A. H., "Moringa oleifera: a food plant with multiple medicinal uses," Phytotherapy Research, 2007, 21(1), 17-25. https://doi.org/https://doi.org/10.1002/ptr.2023.

[12] Gopalakrishnan, L., Doriya, K., \& Kumar, D. S., "Moringa oleifera: A review on nutritive importance and its medicinal application," Food Science and Human Wellness, 2016. 5(2), 49-56. https://doi.org/10.1016/j.fshw.2016.04.001.

[13] Fahey, J. W., Moringa oleifera: A Review of the Medical Evidence for Its Nutritional, Therapeutic, and Prophylactic Properties. Part 1., 24. 2005.

[14] Pari, L., \& Kumar, A. N., "Hepatoprotective Activity of Moringa oleifera on Antitubercular Drug-Induced Liver Damage in Rats," Journal of Medicinal Food, 2005. https://doi.org/http://doi.org/10.1089/10966200260398206.

[15] Toppo, R., Roy, B. K., Gora, R. H., Baxla, S. L., \& Kumar, P. "Hepatoprotective activity of Moringa oleifera against cadmium toxicity in rats," Veterinary World, 2015, 8(4), 537-540. https://doi.org/10.14202/vetworld.2015.537-540.

[16] Mera, I. F. G., Falconí, D. E. G., \& Córdova, V. M., "Secondary metabolites in plants: Main classes, phytochemical analysis and pharmacological activities," Revista Bionatura, 2019. https://doi.org/10.21931/RB/2019.04.04.11

[17] Gebregiorgis Amabye, T., \& Mekonen Tadesse, F., "Phytochemical and Antibacterial Activity of Moringa Oleifera Available in the Market of Mekelle," Journal of Analytical \& Pharmaceutical Research, 2016 , 2(1). https://doi.org/10.15406/japlr.2016.02.00011.

[18] Khatib, M, S. Toxicological and Pharmacological Use of Anticancer Compounds. $\quad$ Springer, 2014 Vol. 3, pp. 227 https://books.google.co.ke/books?id=PetiDwAAQBAJ\&pg=PA227\&1 $\mathrm{pg}=\mathrm{PA} 227 \& \mathrm{dq}=$ Khatib,$+2014+$ moringa\&source $=$ bl\&ots $=$ IwuTzQVC eE\&sig=ACfU3U1CAXpR3iEIRKuiGHuedQkRIunM4Q\&hl=en\&sa =X\&ved=2ahUKEwil5ePrgp3yAhULkRQKHbftDvgQ6AF6BAgXE $\mathrm{AM} \# \mathrm{v}=$ onepage $\& \mathrm{q}=\mathrm{Khatib} \% 2 \mathrm{C} \% 202014 \% 20$ moringa $\& \mathrm{f}=$ false

[19] Chinedu, A., Ajibaye, O., Anyasor, G., Fakoya, O., \& Okebugwu, O. Effect of Extraction Solvents on Phenolic, Flavonoid and Antioxidant Activities of Three Nigerian Medicinal Plants. Nature and Science, 2011 9(7). file:///C:/Users/Hp/Desktop/paperpub.pdf

[20] Jorgensen, E, J., Deyang, X., Christoph, C., Heidi, A, E., David, R., Mohammed, S, M et al. Origin and evolution of transporter substrate specificity within the NPF family. E-life. 2017 https://doi.org/10.7554/eLife.19466.001

[21] Torres-Castillo, J. A., Sinagawa-García, S. R., Martínez-Ávila, G. C. G., López-Flores, A. B., Sánchez-González, E. I., Aguirre-Arzola, V. E., Gutiérrez-Díez, A., "Moringa oleifera: Phytochemical detection, antioxidants, enzymes and antifugal properties," Phyton, 2013, 82, 193-202.

[22] Torres-Castillo, J. A., Sinagawa-García, S. R., Martínez-Ávila, G. C. G., López-Flores, A. B., Sánchez-González, E. I., Aguirre-Arzola, V. E., Gutiérrez-Díez, A., "Moringa oleifera: Phytochemical detection, antioxidants, enzymes and antifugal properties," Phyton, 2013, 82, 193-202.

[23] Nayak, G., Rao, A., Mullick, P., Mutalik, S., Kalthur, S. G., Adiga, S. K., \& Kalthur, G., "Ethanolic extract of Moringa oleifera leaves alleviate cyclophosphamide-induced testicular toxicity by improving endocrine function and modulating cell specific gene expression in mouse testis," Journal of Ethnopharmacology, 2020, 259. https://doi.org/10.1016/j.jep.2020.112922.

[24] Makita, C., Chimuka, L., Steenkamp, P., Cukrowska, E., \& Madala, E., "Comparative analyses of flavonoid content in Moringa oleifera and Moringa ovalifolia with the aid of UHPLC-qTOF-MS fingerprinting,' South African Journal of Botany, 2016, 105, 116-122. https://doi.org/10.1016/j.sajb.2015.12.007.

[25] Ravindra, A. V., Priya, R., \& Siddheshwar, S. A., "Pharmacological Review on Moringa Oleifera," World Journal of Pharmaceutical Research, 2019, 88(8), 910-920.

[26] Das, S. K., J., B. D., P.V., P., Das, S., Behera, S. P., Veilumuthu, P., \& Christopher, J. G., "Investigation on the Phenolic Content in Moringa oleifera and Its Antimicrobial Activity," Indian Journal of Agricultural Research, (Of). 2020. https://doi.org/10.18805/ijare.a-5636.

[27] Elgamily, H., Moussa, A., Elboraey, A., El-Sayed, H., Al-Moghazy, M., \& Abdalla, A., "Microbiological assessment of Moringa oleifera extracts and its incorporation in novel dental remedies against some oral pathogens," Macedonian Journal of Medical Sciences, 2016, 4(4) 585-590. https://doi.org/10.3889/oamjms.2016.132. 
[28] Kumari, C., Virk, A. K., Kumari, S., Gupta, T., Rolta, R., Li, X., \& Kulshrestha, S., "Identification of potential targets for Thymidylate Synthase and Amp-C Blactamase from of non-alkaloidal fractions of Moringa oleifera leaves," Current Pharmaceutical Biotechnology, 2021, 22. https://doi.org/10.2174/138920102266621011.

[29] Yee, M. M. A., "Comparative Studies on Antimicrobial Activity and Antioxidant Activity on Different Extracts of Leaf, Bark and Root of Moringa oleifera Lamk (Drumstick tree)," International Journal of Recent Innovations in Academic Research ISSN, 2019. 3(7), 24-34.

[30] Enwa, F. O., Omojate, C. G., \& Adonu, C. C., "A review on the phytochemical profile and the antibacterial susceptibility Pattern of some clinical isolates to the ethanolic leaves extract of Moringa oleifera LAM,” International Journal of Advanced Research, 2013, 1(2320), 226-238.
[31] Kou, X., Li, B., Olayanju, J. B., Drake, J. M., \& Chen, N., "Nutraceutical or pharmacological potential of Moringa oleifera Lam," 2018. Nutrients. https://doi.org/10.3390/nu10030343.

[32] Metwally, F. M., Rashad, H. M., Ahmed, H. H., Mahmoud, A. A., Abdol Raouf, E. R., \& Abdalla, A. M., "Molecular mechanisms of the anti-obesity potential effect of Moringa oleifera in the experimental model," Asian Pacific Journal of Tropical Biomedicine, 2017, 7(3), 214-221. https://doi.org/10.1016/j.apjtb.2016.12.007.

[33] Okoro, S.O, Kawo, A. H. and A., "Phytochemical Screening, Antibacterial and Toxicological," Bayero Journal of Pure and Applied Sciences, 2014, 7(1), 105-115. 